\title{
ADOÇÃO INTERNACIONAL E SEUS PROCEDIMENTOS
}

Bianca Stephanie Cita, Prof. Me.Ricardo Gabriel de Araújo

Universidade do Oeste Paulista, Curso de Direito, Presidente Prudente, SP. E-mail: bianca cita@hotmail.com

\begin{abstract}
RESUMO
O presente artigo visa a conceituar e explanar os procedimentos da Adoção Internacional, trazendo os importantes pontos dessa modalidade de adoção. A metodologia constou de pesquisas bibliográficas, resultante de leitura e análise de leis, tratados e artigos eletrônicos. Os dados obtidos foram analisados utilizando-se do método hipotético dedutivo. Os resultados são satisfatório nos casos em que a adoção nacional não se torna possível, beneficiando o menor que não tenha possibilidade de ingressar em uma nova família em seu país de origem. Concluímos que, este tipo de adoção se faz importante, pois é através dele que o menor obtém oportunidade de crescer em um ambiente familiar sadio. Por fim, visa-se divulgar esta modalidade de adoção, pois ainda que se tenha regulamentação sobre o tema se demonstra pouco divulgado no âmbito universitário, familiar e coletivo.
\end{abstract}

Palavras-chave: Adoção. Adoção Internacional. Menor. Família. Interesse do menor.

\section{INTERNATIONAL ADOPTION AND ITS PROCEDURES}

\begin{abstract}
This article aims to conceptualize and explain the procedures of International Adoption, bringing the important points of this modality of adoption. The methodology consisted of bibliographical research, resulting from reading and analysis of laws, treaties and electronic articles. The data obtained were analyzed using the hypothetical deductive method. The results are satisfactory in cases where national adoption is not possible, benefiting the child who is not able to join a new family in their country of origin. We conclude that this type of adoption becomes important because it is through him that the child gets the opportunity to grow up in a healthy family environment. Finally, it is intended to publicize this modality of adoption, because even if there is regulation on the subject it shows little dissemination in the university, family and collective.

Keywords: Adoption, International Adoption, Minor, Family, interest of the child.
\end{abstract}




\section{INTRODUÇÃO}

A adoção na modalidade internacional teve origem em 1627. Contudo, esta somente foi ganhando regulamentação após a segunda guerra mundial, onde muitas crianças ficaram órfãs, sem a possibilidade de continuar a viver com sua família em seu país de origem. Com esse cenário, se tornou propício o tráfico de menores, pois muitos desses não portavam documentos ante a ausência de regulamentação específica à época para que fosse realizada a adoção na modalidade internacional, esses menores acabavam sendo utilizados para exploração sexual, trabalho escravo e outros.

Com o passar dos anos, os Estados começaram a regulamentar norma que garantisse o bem estar dos menores em novas famílias fora do seu país de origem, definindo essa modalidade de adoção, através da Convenção de Haia.

Dessa forma, o Brasil por ser signatário dessa Convenção, aderiu o procedimento da adoção internacional, como medida excepcional na Constituição Federal em seu artigo 227, §5o e artigos 51 e seguintes do Estatuto da Criança e do Adolescente (ECA).

Portanto, cabe destacar entre o procedimento da adoção nessa modalidade, que embora seja caso excepcional no Brasil, traz a oportunidade do menor pertencer a uma nova família, depois de esgotadas todas as suas possibilidades em seu país de origem.

Assim, o objetivo do presente trabalho é trazer à baila o instituto da Adoção Internacional com objetivo de explanar, em síntese, o que vem a ser, bem como o que se objetiva.

\section{METODOLOGIA}

Os dados deste artigo foram obtidos por meio da aplicação do método hipotéticodedutivo. Tal método tem a finalidade de apontar uma viável e possível solução a um problema existente ao enfrentá-lo, partindo de uma análise do geral ao particular. Ademais, utilizou-se da pesquisa bibliográfica, resultante da leitura e análise de leis, tratados e artigos eletrônicos que se fizeram produtivos para elaboração deste trabalho.

\section{DISCUSSÃO}

A adoção é ato pelo qual uma pessoa passa a ter vínculos jurídicos com outra, na situação de filho. Noutras palavras (DINIZ, 2015, p. 576),

$A$ adoção vem a ser o ato judicial pelo qual, observados os requisitos legais, se estabelece, independentemente de qualquer relação de parentesco consanguíneo ou afim, um vinculo fictício, trazendo para sua família, na condição de filho, pessoa que, geralmente, Ihe é estranha. Da origem, portanto, a uma relação jurídica de parentesco civil entre adotante e adotado. É uma ficção legal que possibilita que se constitua entre o adotante e o adotado um laço de parentesco de 10 grau na linha reta.

A adoção é, portanto, um vínculo de parentesco civil, em linha reta, estabelecendo entre adotante, ou adotantes, e o adotado um liame legal de paternidade e filiação civil.

Assim, a adoção deve priorizar sempre o superior interesse do menor, como estabelecido no artigo 100, do Estatuto da Criança e do Adolescente (ECA), sendo que segundo Venosa (pág. 299, 2016), "o enfoque da adoção atual terá em vista, contudo, a pessoa e o bemestar do adotando, antes dos interesses dos adotantes".

Com o passar dos anos o instituto da adoção foi sendo modificado e se adequando aos ordenamentos de cada Estado, no ordenamento brasileiro, as questões relativas às crianças foram inseridas pela Constituição Federal de 1988 e pelo ECA, sendo satisfatório o processo de preservação do superior interesse do menor, com a aprovação da Convenção de Haia em 1993, 
e a promulgação da mesma em 1999,pelo Brasil, a partir daí a adoção passou por modificações significativas no ordenamento brasileiro, com a Lei no 12.010/09.

A Convenção dos direitos das crianças de 1989 expõe em seu artigo 34, o ponto mais importante referente à proteção dos menores contra o abuso e exploração sexual, para que possa evitar a existência de outra finalidade na adoção internacional. Assim, a Convenção atribuiu ao Estado à proteção da criança, sendo garantidor de um ambiente saudável ao adotando.

Essa Convenção deu uma visão internacional à criança, preservando seus direitos e interesses, podendo ser vista como a continuidade de uma família, a possibilidade de que haja futuro e de que, assim como qualquer ser humano, ela possui valores, direitos e deveres.

Outra Convenção que deu importância aos interesses dos menores e conservação aos seus direitos foi a Convenção de Haia, aprovada em 1993 e promulgada no Brasil em 1999, pelo decreto 3.087, que juntamente com o Estatuto da Criança e do Adolescente regulam o instituto da adoção no país. Os objetivos da Convenção de Haia foram estabelecidos em seus primeiro artigo:

\begin{abstract}
ARTIGO 1. A presente Convenção tem por objetivo: a) estabelecer garantias para que as adoções internacionais sejam feitas segundo o interesse superior da criança e com respeito aos direitos fundamentais que Ihe reconhece o direito internacional; b) instaurar um sistema de cooperação entre os Estados contratantes que assegure o respeito às mencionadas garantias e, em conseqüência previna o seqüestro, a venda ou o tráfico de crianças; c) assegurar o reconhecimento nos Estados contratantes das adoções realizadas segundo a Convenção (1993).
\end{abstract}

Regulamentou a adoção internacional entre os estados como forma de superar os conflitos, trazendo leis materiais, procedimentais e indiretas de conflitos. A fim de não dificultar o procedimento da adoção, mas sim de preservar a eficácia, com tratamento igualitário entre os países, tanto como o de origem como de acolhida, extirpando o tráfico e exploração sexual.

No Brasil, a adoção está regulamentada pelo ECA junto às convenções promulgadas pelo país, porém, nem sempre foi assim, somente após a Lei $n$ ㅇ 12.010/09, que revogou os artigos 1.620 e 1.629 do CC, prevalecendo somente a adoção plena, estipulada pelo ECA.

Com tantas modificações e melhorias a adoção se tornou cada vez mais humanitária, sendo medida excepcional a introdução do menor em família substituta, devendo ser destinada a proteção daquelas crianças e adolescentes que se encontravam com seus direitos fundamentais ameaçados. (VENOSA, 2016).

Pensando no interesse do menor, Venosa (VENOSA, 2016, p. 310), traz que,

a colocação em família substituta deverá sistematicamente verificar o interesse do menor, que será ouvido sempre que possível, levando-se em conta o grau de parentesco e grau de afinidade, a fim de evitar ou minorar as consequências decorrentes da medida. 0 maior de 12 anos de idade será necessariamente ouvido, como dispõe o §2ㅇ do art. 28 do ECA, introduzido pela lei da Adoção. Considerando que a colocação em família substituta sempre dependerá de decisão judicial, avulta de importância a atividade do juiz e dos órgãos auxiliares que atuam no campo social e psicológico.

Dessa forma, é nítido observar que o menor somente é introduzido em família substituta depois de esgotadas as possibilidades de conviver entre a família natural. No caso da adoção internacional, esta é à exceção do instituto da adoção, pois somente após todas as tentativas de inserção do menor em família substituta no seu país de origem e que o menor será colocado a adoção internacional, veja-se no art. 51, §1으, II do ECA, in verbis:

Art. 51. Considera-se adoção internacional aquela na qual o pretendente possui residência habitual em país-parte da Convenção de Haia, de 29 de maio de 1993, 
Relativa à Proteção das Crianças e à Cooperação em Matéria de Adoção Internacional, promulgada pelo Decreto no 3.087, de 21 junho de 1999, e deseja adotar criança em outro país-parte da Convenção.

§ $10 \mathrm{~A}$ adoção internacional de criança ou adolescente brasileiro ou domiciliado no Brasil somente terá lugar quando restar comprovado:

II - que foram esgotadas todas as possibilidades de colocação da criança ou adolescente em família adotiva brasileira, com a comprovação, certificada nos autos, da inexistência de adotantes habilitados residentes no Brasil com perfil compatível com a criança ou adolescente, após consulta aos cadastros mencionados nesta Lei; (Redação dada pela Lei no 13.509, de 2017)

O ilustre doutrinador Paulo Nader (2016, pag. 381) nos mostra os pontos excepcionais, como forma de interpretar o descrito no artigo acima, assim:

A adoção internacional de criança e adolescente é medida excepcional em nosso ordenamento, admitida apenas para a hipótese em que ficar provado: a) que a colocação em família substituta é solução indicada para o caso em concreto; b) não ser possível a colocação da criança ou adolescente em família substituta brasileira; c) em se tratando de adolescente, que este se encontra preparada para a adoção, à vista de parecer formulado por equipe interprofissional após a oitiva do menor e de sua anuência perante o juiz.

Além de estar regulamentada como medida excepcional existe a prioridade da adoção internacional no ordenamento brasileiro, que é o fato do menor ser adotado por brasileiro que reside no exterior.

Para que seja realizada a adoção, devem ser seguidos alguns requisitos.

$O$ adotante deverá ter mais de 18 anos e ter 16 anos a mais do que o adotado, isto, pois, segundo Paulo Nader (NADER,2016, pag. 369),

A diferença de idade se explica sob vários aspectos. Espera-se que o adotante tenha maior experiência de vida, a fim de que possa bem orientar o adotado. Presume-se, por outro lado, que a diferença apontada favoreça a natural ascendência moral que deve existir na relação entre pai e filho. Busca-se, também, afastar interesse de ordem sexual entre ambos. Nota-se, de pronto, que a importância da exigência legal é meramente relativa, pois não garante que a finalidade da disposição seja alcançada.

A diferença mínima de idade é coincidente com a idade núbil, ou seja, a adoção visa imitar a natureza humana, e está previsto o requisito da idade no artigo 42 , § 3으, do ECA.

Além da idade, o adotante deverá estar apto moral e economicamente, estando disposto para educar, criar e amar o adotando. O estado civil pouco importa, atingida a idade exigida, torna-se possível o ato de adotar, mas no caso de adoção conjunta os adotantes precisam ser casados civilmente, ou manterem união estável.

Dessa forma o §4ㅇ faz menção a exceção, para que aqueles casais divorciados ou separados judicialmente possam adotar se for para preservar o interesse do menor:

Art. $42(\ldots)$

§ 40 Os divorciados, os judicialmente separados e os ex-companheiros podem adotar conjuntamente, contanto que acordem sobre a guarda e o regime de visitas e desde que o estágio de convivência tenha sido iniciado na constância do período de convivência e que seja comprovada a existência de vínculos de afinidade e afetividade com aquele não detentor da guarda, que justifiquem a excepcionalidade da concessão. (Redação dada pela Lei no 12.010, de 2009).

Porém, é necessário que se comprove que não há impedimento para a adoção, como estabelecido pelo artigo 29, e que o estágio de convivência se realizou enquanto estavam juntos. 
Já adotando deverá ser considerado pelo Estado que é adotável, sendo um dos requisitos mais importantes. Em nosso ordenamento a idade do adotado vai de zero a dezoito anos de idade, tornando fácil a comprovação por meio da certidão de nascimento do menor.

Aquelas crianças até doze anos incompletos necessitam de consentimento dos pais para a adoção, exceto quando aqueles estão desaparecidos ou destituídos do poder familiar.

Segundo Gonçalves (2016, pág. 394), deverá haver"[...] c) consentimento dos pais ou dos representantes legais de quem se deseja adotar; d) concordância deste, se contar mais de 12 anos (art. 28,§2); e) processo judicial (art. 47, caput); f)efetivo benefício para o adotando (art. 43). (grifos nossos).

Para que haja um acompanhamento da adoção que será realizada, é realizado um cadastro do menor e do adotante aptos à adoção, sendo controlado pela Justiça da infância e da juventude da comarca ou do fora regional, é o que estabelece o artigo 50, do ECA.

Seguindo os artigos do Estatuto, o artigo 51, traz sobre os pressupostos necessários à adoção:

Art. 51. Considera-se adoção internacional aquela na qual a pessoa ou casal postulante é residente ou domiciliado fora do Brasil, conforme previsto no Artigo 2 da Convenção de Haia, de 29 de maio de 1993, Relativa à Proteção das Crianças e à Cooperação em Matéria de Adoção Internacional, aprovada pelo Decreto Legislativo $\mathrm{n}$ o 1, de 14 de janeiro de 1999, e promulgada pelo Decreto no 3.087, de 21 de junho de 1999. §1o. A adoção internacional de criança ou adolescente brasileiro ou domiciliado no Brasil somente terá lugar quando restar comprovado: I - que a colocação em família substituta é a solução adequada ao caso concreto; II - que foram esgotadas todas as possibilidades de colocação da criança ou adolescente em família substituta brasileira, após consulta aos cadastros mencionados no art. 50 desta Lei; III - que, em se tratando de adoção de adolescente, este foi consultado, por meios adequados ao seu estágio de desenvolvimento, e que se encontra preparado para a medida, mediante parecer elaborado por equipe interprofissional, observado o disposto nos $\S \S 10$ e 20 do art. 28 desta Lei.

Poderá ser dispensada a documentação do rol do artigo 51 do Estatuto da Criança e do Adolescente, caso seja provado que o adotante estrangeiro tenha intenção de permanecer no Brasil, prevalecerá a Lei do domicilio, conforme artigo 7ํㅡ, do LINDB. (RODRIGUES, 2016).

$O$ primeiro requisito a ser analisado é se estão esgotadas as possibilidades de adoção no Brasil, pois se considera importante preservar as raízes culturais do adotando, tornando-se menos impactante com alteração do país e adequação ao novo seio familiar.

É de grande importância em todo processo de adoção o acompanhamento do adotado, pela equipe interprofissional, mencionada no inciso III, do artigo 51 . Que propicia o maior entendimento das dificuldades apresentadas em todo o processo de transição.

De alguma maneira os adotantes e os adotados são orientados para que possa haver adaptações da construção da nova família e esse processo ocorre no estágio de convivência e, após o estágio há adoção definitiva conferida em sentença.

Esta equipe, além do acompanhamento de todo o processo, também propicia uma maior segurança ao magistrado, pois é ela que acompanha e orienta em todo o procedimento, desde o cadastro até a adoção definitiva. Conforme previsto no artigo 151, do ECA.

Art. 151. Compete à equipe interprofissional dentre outras atribuições que lhe forem reservadas pela legislação local, fornecer subsídios por escrito, mediante laudos, ou verbalmente, na audiência, e bem assim desenvolver trabalhos de aconselhamento, orientação, encaminhamento, prevenção e outros, tudo sob a imediata subordinação à autoridade judiciária, assegurada a livre manifestação do ponto de vista técnico. 
Por conta disso, o magistrado se vê mais seguro ao aplicar a sentença, pois uma equipe específica acompanhou e realizou laudos durante o procedimento e irá acompanhar após a respeitável sentença procedente.

Esta equipe segundo Paulo Nader (2016, p. 366) é, "formada por psicólogos, psicanalistas, pedagogos e assistentes sociais".

Ainda assim há algumas exceções referentes ao prévio cadastro realizado dos pretendentes a adoção que domiciliados no Brasil, descritos no artigo 50, §13, do Estatuto da criança e do adolescente.

Art.50 [...]

$\S 13$. Somente poderá ser deferida adoção em favor de candidato domiciliado no Brasil não cadastrado previamente nos termos desta Lei quando:

I - se tratar de pedido de adoção unilateral;

II - for formulada por parente com o qual a criança ou adolescente mantenha vínculos de afinidade e afetividade;

III - oriundo o pedido de quem detém a tutela ou guarda legal de criança maior de 3 (três) anos ou adolescente, desde que o lapso de tempo de convivência comprove a fixação de laços de afinidade e afetividade, e não seja constatada a ocorrência de má-fé ou qualquer das situações previstas nos arts. 237 ou 238 desta Lei.

Após o cadastro e a compatibilidade entre o adotante e o adotado, estes passam pelo estágio de convivência, para que haja adaptação entre ambas as partes, sendo este requisito caráter obrigatório, exceto na hipótese elencada no artigo $46, \S 10$ do Estatuto, que são os casos de guarda e tutela.

$\mathrm{Na}$ adoção internacional o prazo de estágio de convivência é de no mínimo 30 dias, independente da idade do adotando, conforme estabelecido no artigo 46, §3ㅇ, ECA.

Carlos Roberto Gonçalves (apud RODRIGUES, 2016, p. 397) traz que,

a finalidade do estágio de convivência é "comprovar a compatibilidade entre as partes e probabilidade de sucesso a adoção. Daí determinar a lei a sua dispensa, quando o adotando já estiver na companhia do adotante durante tempo suficiente para se poder avaliar a convivência da constituição do vinculo".

O estágio de convivência é indispensável nos casos de adoção internacional, devendo ser respeitado. Em se tratando de adotando maior é indispensável à assistência do Poder Público.

$\mathrm{Na}$ adoção internacional não há mais possibilidade de adoção por procuração, é necessário o estágio de convivência; comprovação da habilitação do adotante à adoção; apresentação de relatório nacional e estrangeiro; juntada aos autos dos documentos estrangeiros, expedição do laudo de habilitação à adoção internacional; formalização do pedido de adoção perante o juízo da infância e juventude; permissão da saída do adotando do território nacional e atender as solicitações das autoridades sobre o estado da criança a qualquer momento. A adoção seja ela nacional ou internacional terá efeitos pessoais e patrimoniais.

No mais, na adoção também é possível anulação judicial nos casos de prescrição, conformes o artigo 166, V e VI do Código Civil e caso não haja cumprimento dos devidos requisitos estabelecido nos artigos 42 e 44 do ECA e artigos 166, VI e 167, do mesmo Estatuto.

\section{CONCLUSÃO}

Denota-se, portanto, que embora a adoção internacional seja a exceção do instituto, é de extrema importante, pois possibilita ao menor depois de esgotadas suas possibilidades no seu país de origem, de poder viver em um ambiente familiar saudável. Ademais, esta dará ao menor oportunidade de uma boa educação, alimentação, cuidados essenciais, isso sem contar no amor e carinho que a nova família pode propiciar ao adotado, mostrando até mesmo uma nova cultura e novos preceitos para uma boa convivência. 
Isto posto, fica demonstrada em grande proporção que a adoção internacional além de beneficiar os interesses do menor, possui caráter humanitário e visa ao bem estar do adotando.

\section{REFERÊNCIAS}

Adoção Internacional e a convenção de haia no direito brasileiro >https://monografias.brasilescola.uol.com.br/direito/adocao-internacional-convencao-haia-nodireito-brasileiro.htm< Acesso em 05 de maio de 2018.

Adoção internacional no ordenamento jurídico brasileiro e a possibilidade de tráfico de crianças e adolescentes >http://ambitojuridico.com.br/site/?n_link=revista_artigos_leitura\&artigo_id=13706\&revista_caderno=12< Acesso em 05 de maio de 2018.

Adoção internacional de crianças pela Convenção de Haia aplica-se apenas a países ratificantes >http://www.sdh.gov.br/noticias/2015/dezembro/adocao-internacional-de-criancas-pelaconvencao-de-haia-aplica-se-apenas-a-paises-ratificantes< Acesso em 05 de maio de 2018.

Adoção internacional >https://mirisveiga1.jusbrasil.com.br/artigos/151592658/adocaointernacional< Acesso em 01 de maio de 2018.

BRASIL. Estatuto da criança e do adolescente (1990). Estatuto da criança e do adolescente : Lei n. 8.069, de 13 de julho de 1990, Lei n. 8.242, de 12 de outubro de 1991. - 3‥ Ed. - Brasília : Câmara dos Deputados, Coordenação de. Publicações, 2001.

Convenção relativa à proteção das crianças a à cooperação em matéria de adoção internacional. >http://www.planalto.gov.br/ccivil_03/decreto/d3087.htm< Disponível em: Acesso em 07 de maio de 2018.

Declaração universal dos direitos da criança - 1959. Disponível em:< http://www.dhnet.org.br/direitos/sip/onu/c_a/lex41.htm > Acesso em 05 de maio de 2018.

DINIZ, Maria Helena. Curso de direito civil brasileiro, volume 5: direito de família. 30․ Ed. São Paulo : Saraiva, 2015.

Especialistas alertam: adoção de crianças no exterior só deve ser feita em casos excepcionais >https://nacoesunidas.org/especialistas-alertam-adocao-de-criancas-no-exterior-so-deve-serfeita-em-casos-excepcionais/< Acesso em 05 de maio de 2018.

GONÇALVES, Carlos Roberto. Direito civil brasileiro, vol. 6: Direito de família. 13‥ Ed. São Paulo: Saraiva, 2016.

Adoção Internacional: Convenção de Haia. Reflexos na Legislação Brasileira. 20 Ed. São Paulo: Malheiros,2003,.

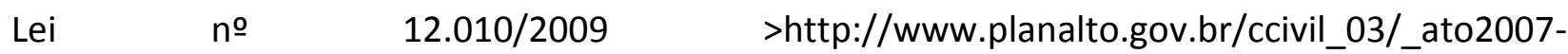
2010/2009/lei/l12010.htm< Acesso em 01 de maio de 2018. 
NADER, Paulo. Curso de direito civil, v.5: direito de família. Rio de janeiro: forense, 2016.

VENOSA, Silvio de Salvo. Direito civil: direito de família. 16․ Ed. rev. Atual. São Paulo: atlas, 2016.

UNICEF BRASIL. Convenção Sobre os Direitos da Criança. Disponível em: https://www.unicef.org/brazil/pt/resources_10120.htm >Acesso em 05 de maio de 2018. 